\title{
Stimulation by Glucose of the Blood Flow to the Pancreatic Islets of the Rat
}

\author{
L.Jansson and C. Hellerström \\ Department of Medical Cell Biology, University of Uppsala, Uppsala, Sweden
}

\begin{abstract}
Summary. Blood flow to the pancreatic islets of the rat was estimated with the microsphere technique. Experiments with microspheres of different sizes (diameter 10,15 or $50 \mu \mathrm{m}$ ) showed that optimal results were obtained with $10-\mu \mathrm{m}$ spheres. Localization of microspheres either within or outside the islets was accomplished by freeze-thawing of the pancreas, making it transparent, so that both islets and microspheres could be distinguished in dark field illumination. Thus, microscopic examination of the freeze-thawed pancreas allowed the microspheres to be counted separately in both the endocrine and exocrine parenchyma. Under basal conditions, pancreatic blood flow was calculated as $0.60 \mathrm{ml} \cdot \mathrm{min}^{-1} \cdot \mathrm{g}^{-1}(\mathrm{w} / \mathrm{w})$. The islets accounted for about $10 \%$ of the total pancreatic blood flow, corresponding to $0.069 \mathrm{ml} / \mathrm{min}$ per whole pancreas. A bolus dose of glucose increased pancreatic blood flow to
\end{abstract}

$0.75 \mathrm{ml} \cdot \mathrm{min}^{-1} \cdot \mathrm{g}^{-1}(p<0.05)$, while the fractional islet blood flow rose to $15.1 \%(p<0.001)$ corresponding to $0.125 \mathrm{ml}$. $\mathrm{min}^{-1}$. pancreas $^{-1}(p<0.001)$. The glucose-induced increase in pancreatic blood flow mainly resulted from increased flow to the pancreatic tail, while the corresponding increase in islet blood flow was uniformly distributed throughout the pancreas. Injection of the non-metabolizable glucose-derivate, 3-0-methyl-D-glucose, affected neither the pancreatic nor the islet blood flow. The data indicate that the islets receive more of the pancreatic blood flow than would be accounted for by their relative volume and that glucose preferentially stimulates blood flow to the islets.

Key words: Pancreatic islets, microcirculation, glucose-stimulation, islet blood flow, rats
Insulin release from the pancreatic B cell may be influenced not only by nervous signals or variations in the concentrations of nutrients and hormones in the immediate cellular environment, but also by changes in islet blood flow. The possible significance of the latter mechanism has been difficult to evaluate, since the islets are distributed within the pancreas as a large number of small cell aggregates which are not easily accessible for direct quantitative studies of blood flow. Early attempts to investigate the islet microcirculation with intravital microscopy suggested that wide variations occur in the blood flow to the islets, which seemed related to the functional state of the $\mathrm{B}$ cells $[1,4,5,28]$. More recent studies indicate that blood flow to the whole pancreas may increase under conditions which stimulate insulin release $[6,7,33]$, but these observations have been difficult to interpret, since the endocrine and exocrine parts of the gland may not share the same mechanisms for regulating blood flow [35].

The introduction of the microsphere method for studies of organ blood flow [32] and its intra-organ distribution provided a means of measuring islet blood flow separately from that of the exocrine parenchyma. However, a prerequisite for this approach is a method for detecting and counting microspheres in the islets as distinct from those in the surrounding exocrine parenchyma. This problem has recently been dealt with either by selectively staining the islets with dyes $[22,29]$ or by clearing the exocrine tissue by freeze-thawing followed by dark field microscopy for identification of islets and microspheres [18]. In the present study, the latter technique has been used to measure the blood flow to the pancreatic islets in rats, both in basal conditions and after administration of glucose.

\section{Materials and Methods}

\section{Administration and Counting of Microspheres}

Adult Sprague-Dawley rats of both sexes weighing $326 \pm 28 \mathrm{~g}$ (mean $\pm \mathrm{SEM}$ ) with free access to food and water were used. Non-radioactive microspheres with a diameter (mean \pm SD) of $10.2 \pm 0.6$, $15 \pm 5$ or $50 \pm 10 \mu \mathrm{m}$ (New England Nuclear, Boston, Massachussetts, USA) were suspended in $0.9 \%(\mathrm{w} / \mathrm{v}) \mathrm{NaCl}$ containing $0.002 \%$ Tween 

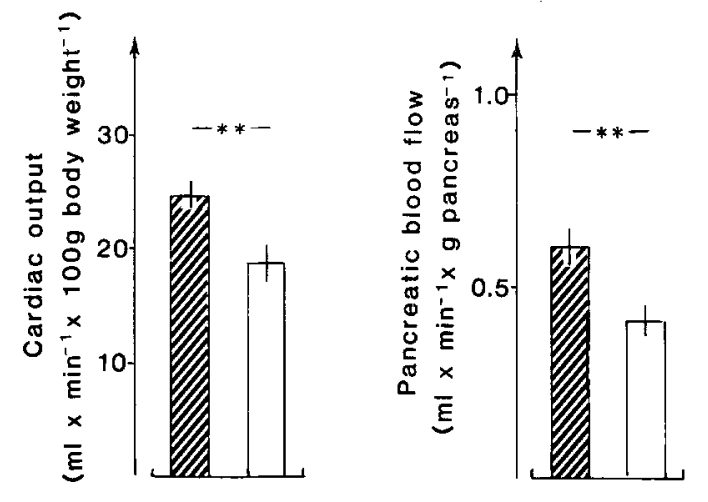

Fig. 1. Cardiac output, pancreatic blood flow, and islet blood flow calculated with the aid of $10 \mu \mathrm{m}$-spheres $(\square n=10)$ and $15 \mu \mathrm{m}$-spheres $(\square n=9)$. $* * p<0.01$, $* * * p 0,001$
20. The animals were anaesthetized with an IP injection of thiobutabarbital sodium $(120 \mathrm{mg} / \mathrm{kg}$ body weight; Inactin, Byk Gulden, Konstanz, FRG). An IV injection of $150 \mathrm{IU}$ of heparin (Heparin $5000 \mathrm{IE} /$ $\mathrm{ml}$, Lövens Läkemedel, Malmö, Sweden) was given simultaneously. Polyethylene catheters were then inserted into the left ventricle or the aortic root (via the right carotid artery) and into the left femoral artery. The position of the catheters was confirmed at autopsy at the end of the experiments. The microspheres were uniformly suspended in the vehicle with the aid of a whirlmixer for at least $10 \mathrm{~min}$ and $0.5 \mathrm{ml}$ of the suspension (containing between $8 \times 10^{4}$ and $1.5 \times 10^{5}$ microspheres) were subsequently injected via the carotid catheter over $20 \mathrm{~s}$. Simultaneously, arterial blood from the femoral artery was withdrawn at a rate of $0.67 \mathrm{ml} / \mathrm{min}$ for $90 \mathrm{~s}$ with the aid of a programmable Microlab M Dispenser (Hamilton Bonaduz, Bonaduz, Switzerland). This reference sample was used to calculate the organ blood flow as described below. Arterial blood pressure and body temperature were monitored throughout the experiments and animals in which the blood pressure varied by $>10 \%$, or the body temperature by $>0.5^{\circ} \mathrm{C}$ were excluded. Immediately after injection of the microspheres, blood samples for determinations of serum glucose and serum insulin concentrations were obtained and the animals killed by cervical dislocation. The pancreas, the adrenals, and the lower lobe of the right lung were quickly removed, blotted and weighed. The pancreas was then divided into three anatomically defined parts corresponding to the head, body and tail. The head is defined as the part attached to the duodenum, the body to the stomach, while the tail represented the unattached, splenic part. The pancreatic tissue was then treated for rapid visualization of the islets with the freeze-thawing technique previously described in detail [18].

After thawing the tissue samples, the number of microspheres in the exocrine and endocrine parts of the gland was counted separately. The reference sample (consisting of $1.0 \mathrm{ml}$ of heparinized blood) was transferred to glass microfibre filters (Whatman, London, UK) with a pore size of $<10 \mu \mathrm{m}$ and the microspheres counted in direct illumination with the aid of a stereo microscope (Olympus SZIII, Olympus, Tokyo, Japan).

The organ blood flow was then calculated according to the formula

$Q_{\text {org }}=\frac{N_{\text {org }} \times Q_{\text {ref }}}{N_{\text {ref }}}$

( $Q_{\text {org }}=$ organ blood flow $(\mathrm{ml} / \mathrm{min}), \mathrm{Q}_{\text {ref }}=$ flow of the reference sample (ml/min), $\mathrm{N}_{\mathrm{org}}=$ number of microspheres present in the organ, $\mathrm{N}_{\text {ref }}=$ number of microspheres present in the reference sample).

For control purposes, the number of microspheres present in each of the adrenal glands was counted in a similar way. If the values for the blood flow in the left and right glands differed by $>10 \%$, this was taken as evidence of inadequate mixing of microspheres, and the experiment was discarded. The number of microspheres present in the lower lobe of the lung was also estimated in order to evaluate the shunting of spheres through peripheral systemic circulatory beds.

\section{Effects of Anaesthesia on Blood Glucose Homeostasis}

Eighteen female Sprague-Dawley rats weighing $271 \pm 18 \mathrm{~g}$ (mean \pm SEM) were anaesthetized with thiobutabarbital sodium as described above. Samples of $50 \mu \mathrm{l}$ blood were removed from a tail vein immediately before injection of the anaesthetic, and then every fifth minute for $60 \mathrm{~min}$. Ten animals received an IP injection of $2 \mathrm{ml}$ of a $30 \%$ $(\mathrm{w} / \mathrm{v})$ solution of either D-glucose (ACO Glucos 30\%, ACO Läkemedel, Solna, Sweden) $(n=5)$ or 3-0-methyl-D-glucose (Sigma Chemicals, St Louis, Missouri, USA) $(n=5)$ immediately after the administration of the anaesthetic. These latter animals were subjected to the same surgical procedure as described above. The serum glucose content of the blood samples was then determined using a Beckman glucose analyzer 2 (Beckman, Fullerton, California, USA), and the serum insulin concentration by radioimmunoassay [12].

\section{Effects of D-Glucose and 3-0-Methyl-D-Glucose on Pancreatic Blood Flow and Islet Blood Flow}

Twelve female Sprague-Dawley rats weighing $280 \pm 17 \mathrm{~g}$ (mean \pm SEM) were anaesthetized and catheterised as described above. Immediately after the injection of Inactin, $2.0 \mathrm{ml}$ of a $30 \%(\mathrm{w} / \mathrm{v})$ solution of either D-glucose or 3-0-methyl-D-glucose was injected IP in seven and five animals, respectively. Microspheres with a diameter of $10.2 \pm 0.6 \mu \mathrm{m}$ (mean \pm SD) were injected $25 \mathrm{~min}$ later and the organ blood flows calculated as described above. Non-treated rats injected with $10-\mu \mathrm{m}$ spheres served as further controls.

\section{Statistical Computations}

All values are expressed as mean \pm SEM. Probabilities $(p)$ of chance differences between the experimental groups were estimated by Student's two-tailed t-test.

\section{Results}

\section{Effects of the Microsphere Size on Blood Flow Measurements}

Depending on the size of the microspheres, there was a marked difference in the calculated flow of blood, both to the whole pancreas and to the islets (Fig.1). As expected, values for cardiac output, pancreatic blood flow (PBF) and islet blood flow (IBF) were higher with the $10 \mu \mathrm{m}$ - than with the $15 \mu \mathrm{m}$-microspheres. Experiments with $50 \mu \mathrm{m}$-spheres provided no reliable flow values, since with these relatively large spheres there was a 
Table 1. Number of microspheres present within the pancreas and in the reference samples in non-injected, 3-0-methyl-glucose-injected, and glucose-injected rats

\begin{tabular}{lccc}
\hline & \multicolumn{3}{l}{ Number of microspheres present } \\
\cline { 2 - 4 } & Control rats & $\begin{array}{l}\text { Glucose-in- } \\
\text { jected rats }\end{array}$ & $\begin{array}{l}\text { 3-0-methyl } \\
\text { glucose in- } \\
\text { jected rats } \\
(n=5)\end{array}$ \\
\hline Whole pancreas & $837 \pm 127$ & $2347 \pm 625$ & $1527 \pm 140$ \\
Exocrine tissue & $762 \pm 115$ & $1993 \pm 532$ & $1366 \pm 128$ \\
Islets & $86 \pm 13$ & $353 \pm 94$ & $161 \pm 14$ \\
\hline Reference sample & $1221 \pm 171$ & $2078 \pm 606$ & $1666 \pm 120$ \\
\hline
\end{tabular}

Results are expressed as mean \pm SEM

change of the cardiovascular dynamics as reflected by a sharp decrease in blood pressure (data not shown). Shunting of $10 \mu \mathrm{m}$ microspheres to the lungs in no case exceeded a value amounting to $1.5 \%$ of the cardiac output. The number of microspheres in the pancreas and reference samples is shown in Table 1 . With the exception of the islets, all values were well above 500 spheres/ pancreas. These combined observations led us to choose $10 \mu \mathrm{m}$ spheres in subsequent experiments.

\section{Effects of Anaesthesia on Serum Glucose Homeostasis}

There were no apparent effects of anaesthesia on the serum glucose levels in the non-operated animals (Fig. 2). In the operated animals, injected with 3-0-methyl-D-glucose, there was a slow but barely significant ( $p<0.05$ for 0 versus $60 \mathrm{~min}$ values) increase in the serum glucose concentration which, however, never exceeded $9 \mathrm{mmol} / 1$ even after $60 \mathrm{~min}$. In the glucose-injected animals, a peak serum glucose value of about $17 \mathrm{mmol} / 1$ was reached after $25 \mathrm{~min}$, i.e. at the time of injection of the microspheres.

\section{Effects of D-Glucose and 3-0-Methyl-D-Glucose on PBF and $I B F$}

At the time of microsphere injection, the serum glucose concentration in the glucose-injected animals was about 2.5 times higher than in that of the two control groups (Table 2). Separate measurements showed that, at this instant, serum insulin in the 3-0-methyl-glucose-injected animals was $1.49 \pm 0.32 \mathrm{ng} / \mathrm{ml}(n=5)$, whereas in the glucose injected group the corresponding value was $2.87 \pm 0.23 \mathrm{ng} / \mathrm{ml}(n=5, p<0.01)$.

As can be seen from Table 2, there were no differences in cardiac output between the three groups of animals. The PBF, however, showed a modest increase after glucose administration both in comparison with non-injected animals and with those injected with 3-0methyl glucose. This glucose-induced increase in PBF seemed to result mainly from increased flow to the pancreatic tail, whereas flow to the body and head of the

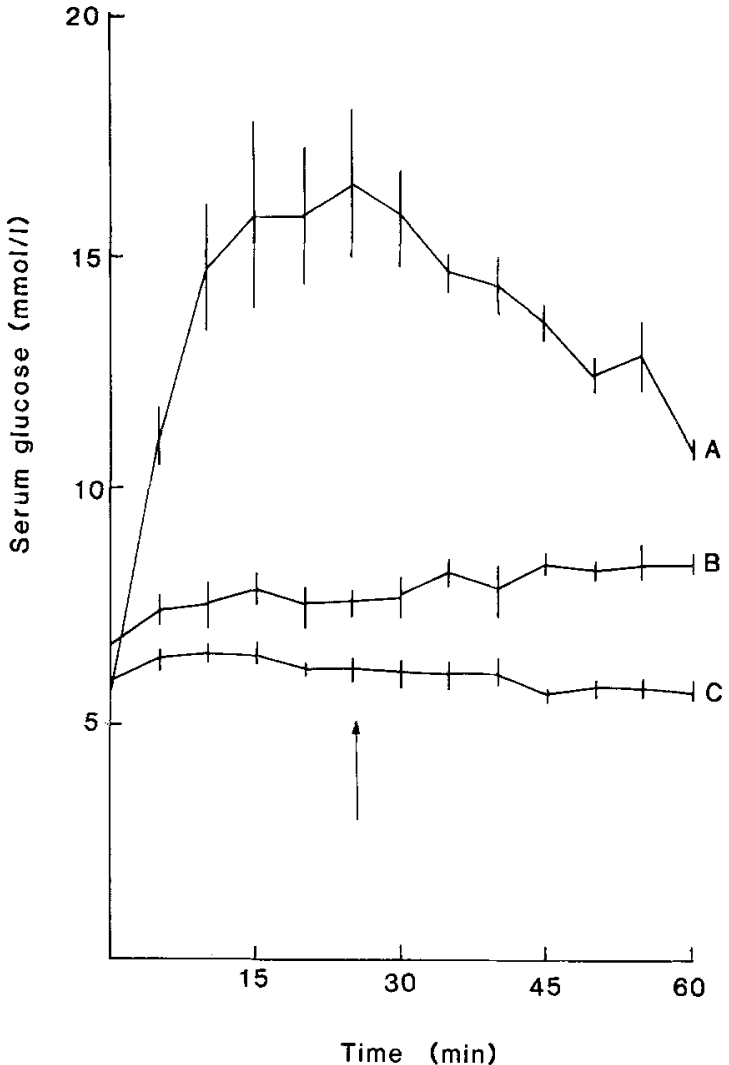

Fig. 2. Serum glucose concentrations followed for $60 \mathrm{~min}$ in $(A)$ glucose-injected, sham-operated rats $(B)$, 3-0-methyl-glucose injected, sham-operated rats $(C)$, non-injected, non-operated rats. The injection of the microspheres was made approximately $25 \mathrm{~min}$ after induction of anaesthesia (arrow)

gland remained unchanged. The PBF was approximately $0.8 \%$ of the cardiac output in both non-injected and $3-0$-methyl glucose injected animals and $1.2 \%$ in the glucose injected group.

In the non-injected animals, the IBF was not less than about $10 \%$ of the PBF and this flow rate was not affected by 3-0-methyl glucose. In addition, there were no apparent regional differences in the pancreas with respect to IBF under these conditions. Therefore, the $\mathrm{IBF} /$ whole pancreas, corresponding to the total blood flow through the islets, could be calculated as about $0.065-0.070 \mathrm{ml} / \mathrm{min}$ in each of the control groups.

Administration of glucose caused a marked and significant increase in IBF, irrespective of the pancreatic regions. This rise in IBF was, indeed, much greater than that in PBF, so that IBF increased by about $80 \%$ while there was only a $25 \%$ increase in PBF. Thus, glucose administration almost doubled the total blood flow to the islets.

\section{Discussion}

In the present study care was taken to meet the methodological demands of the microsphere technique as dis- 
Table 2. The calculated cardiac output, pancreatic blood flow and islet blood flow in non-injected, 3-0-methyl glucose injected, and glucose injected rats

\begin{tabular}{|c|c|c|c|}
\hline & $\begin{array}{l}\text { Non-injected } \\
\text { control rats } \\
(n=9)\end{array}$ & $\begin{array}{l}\text { Glucose injected rats } \\
(n=7)\end{array}$ & $\begin{array}{l}\text { 3-0-methyl } \\
\text { glucose injected } \\
\text { rats } \\
(n=5)\end{array}$ \\
\hline Pancreatic wet weight (mg) & $1153 \pm 55$ & $1093 \pm 84$ & $1089 \pm 89$ \\
\hline Serum glucose concentration $(\mathrm{mmol} / \mathrm{l})$ & $7.6 \pm 0.2$ & $19.6 \pm 2.0^{\mathrm{c}, \mathrm{g}}$ & $7.2 \pm 0.3$ \\
\hline Cardiac output $\left(\mathrm{ml} \cdot \min ^{-1} \cdot \mathrm{g}\right.$ body weight $\left.{ }^{-1}\right)$ & $24.1 \pm 1.2$ & $24.5 \pm 1.2$ & $23.3 \pm 1.1$ \\
\hline $\begin{array}{l}\text { Head } \\
\text { Body } \\
\text { Tail }\end{array}$ & $\begin{array}{l}0.64 \pm 0.09 \\
0.53 \pm 0.06 \\
0.60 \pm 0.05\end{array}$ & $\begin{array}{l}0.72 \pm 0.07 \\
0.65 \pm 0.08 \\
0.78 \pm 0.02^{b, f}\end{array}$ & $\begin{array}{l}0.75 \pm 0.09 \\
0.71 \pm 0.08 \\
0.51 \pm 0.05\end{array}$ \\
\hline $\begin{array}{l}\text { Islet blood flow ( } \% \text { of PBF) } \\
\text { Head } \\
\text { Body } \\
\text { Tail }\end{array}$ & $\begin{array}{r}10.3 \pm 0.5 \\
11.9 \pm 0.8 \\
8.4 \pm 0.9 \\
10.2 \pm 0.6\end{array}$ & $\begin{array}{l}15.1 \pm 0.7^{\mathrm{c,g}} \\
16.3 \pm 1.2^{\mathrm{b}, \mathrm{f}} \\
12.7 \pm 1.0^{\mathrm{b}} \\
15.5 \pm 0.7^{\mathrm{c}, \mathrm{g}}\end{array}$ & $\begin{array}{l}10.5 \pm 0.4 \\
10.4 \pm 0.9 \\
10.9 \pm 1.3 \\
10.6 \pm 0.7\end{array}$ \\
\hline
\end{tabular}

Results expressed as mean \pm SEM

${ }^{\mathrm{a}} p<0.05$ versus control group; ${ }^{\mathrm{b}} p<0.01$ versus control group; ${ }^{\mathrm{c}} p<0.001$ versus control group; ${ }^{\mathrm{e}} p<0.05$ versus 3 -0-methyl-glucose group;

f $p<0.01$ versus 3 -0-methyl-glucose group; ${ }^{g} p<0.001$ versus 3-0-methyl-glucose group

cussed by Lifson [23] with particular regard to measurements of pancreatic blood flow. Thus, uniform mixing of the spheres with the blood at the injection site was optimized by intracardiac injection and this was further confirmed by the observation of similar numbers of spheres in each adrenal gland. Failure to trap such small microspheres was probably not of significance in the present study, since the number of spheres trapped in the lungs was no greater than could be accounted for by the bronchial blood flow itself. This, nevertheless, does not exclude the possibility of local shunting in the pancreas, since spheres shunted through the pancreatic vascular bed may be trapped in the liver and escape detection.

The size of the microspheres is important not only for trapping in the vascular bed but also for even distribution at the branching points of the vessels. Since it is known that larger microspheres tend to travel more centrally in the blood stream [31], it is generally agreed that the smallest spheres that are completely trapped during the first circulation are of the optimal size [8]. The present finding that $10 \mu \mathrm{m}$ was the most suitable average sphere diameter agrees with previous results of Lifson et al. $[23,24]$ who reached the same conclusion after testing both larger and smaller spheres.

A further factor of methodological significance is the number of spheres counted in each organ $[3,17,20]$. Statistical errors are thought to be minimized if the number of spheres counted in a given organ of the rat exceeds 200 [17]. Indeed, this was the case in the measurements in this study of PBF and IBF in glucose-injected animals. Although the precision in measuring
IBF in the control and 3-0-methyl-glucose-injected animals is not as high, it appeared sufficient in view of the small standard errors of the mean in these measurements.

An important prerequisite for studies of the blood flow to the pancreatic islets with the microsphere technique is the correct identification of individual islets and the precise localization of microspheres to these structures. The present method, based on simple freezing and thawing of the pancreas followed by dark field microscopy, has been shown to fulfil these criteria [18] and, furthermore, involves only minimal handling of the pancreas after injection of the spheres. Indeed, dislocation of spheres may be a significant source of error $[10,27]$ in view of the small size of the islets and their relatively wide capillaries. In view of this, methods which involve arterial perfusion with fixatives or staining solutions for visualization of islets would cause some concern due to possible dislocation of the trapped spheres. This may be of particular significance when using intravital staining of islets by pancreatic perfusion with dithizone [29]. In addition to the risk of dislocation by the injected dye, the intravital administration of this compound may lead to vasospasm [2] which might prevent staining of some islets and thus result in erroneously low IBF values.

The present PBF data are in close agreement with those previously reported in the rat $[17,26,30,34]$. This further confirms the suitability of our technique for the correct identification and enumeration of spheres trapped in the pancreatic parenchyma. The PBF values in different pancreatic regions also suggest a uniform 
vascular distribution throughout the pancreas despite the fact that the different pancreatic regions receive quite different arterial supplies. To what extent the apparent selective increase in PBF of the tail portion in response to glucose is related to the arterial supply requires further investigation. It is of interest in this context that recent studies suggest a correlation between the pancreatic arterial supply and the sensitivity of the B cell to the insulin releasing effect of glucagon [19].

In contrast to the relative abundance of data on PBF in various species, so far there are only two detailed reports on quantitative measurements of IBF, one in the rabbit [24] and the other in the rat [29]. While the present percentage values for the IBF agree well with those in the rabbit, a marked discrepancy exists in comparison with those reported in the rat. Thus, the fractional IBF in this latter study was found to be only $1.22 \%$ of the PBF, compared with our value of $10.3 \%$ under basal conditions. Whether this discrepancy is due to differences in methodology or reflects true physiological differences cannot be decided at present. In the study of Meyer et al. [29], the islets were visualized by intravital staining with dithizone followed by clearing of the pancreas with glycerol. In addition, these authors used Wistar rats in contrast with Sprague-Dawley rats in the present study. Furthermore, the methods for anaesthesia were different, in that Meyer et al. [29] employed urethan, which is known to have a beta -blocking effect $^{-}$ [25], whereas thiobutabarbital was used in the present study. To our knowledge, no adverse effects of this latter compound on the splanchnic circulation have been described. Irrespective of the precise reasons for the differences between the two sets of observations, they lead to markedly different interpretations. Thus, when the relative values for IBF are recalculated as flow rates per unit islet weight, assuming a total islet weight of 1-2\% of the adult rat pancreas $[9,15]$, an IBF similar to the $\mathrm{PBF}$ is obtained when the figure of Meyer et al. [29] is used. With the present figure of $10.3 \%$, the IBF is, however, over six times higher than the PBF. The latter observation is in keeping with the general concept that endocrine organs have an ample blood supply and with the light microscopic observation of a rich capillary network in the islets. However, without a satisfactory explanation of the discrepancy between the present data and those of Meyer et al. [29] the value of IBF in relation to that of PBF remains an open question.

The marked increase in IBF caused by glucose was not a mere osmotic effect due to the intraperitoneal infusion of a concentrated glucose solution [21], since there was no corresponding change in IBF when the non-metabolizable glucose derivate 3-0-methyl glucose [16] was injected. Instead, the preferential increase in IBF in response to glucose supports the concept that glucose may participate in the physiological regulation of IBF and, by stimulating IBF in situations with hyperglycaemia, amplify the direct, insulin releasing effects of this substrate on the B cell. A similar effect of glucose was recently reported by Vetterlein et al. [36]. A glucoseinduced enhancement of IBF, therefore, would represent an effect which, in addition to the glucose-induced stimulation of insulin biosynthesis and release, would further emphasize the important physiological role of glucose for the regulation of the blood insulin level.

It is conceivable that a stimulatory effect of glucose on IBF would be mediated either by local mechanisms and/or by nervous or humoral influences. It is well known that glucose markedly stimulates the metabolic rate of the islet B cell and, therefore, local thermogenesis [11] or a local drop in blood oxygen saturation [13, 14] might enhance the islet blood flow. On the other hand, nervous vasodilator signals could be of equal or more importance, since glucoreceptors are known to exist in the central nervous system and a rich innervation is found in the walls of pancreatic blood vessels.

Acknowledgements. This work was presented in part at the 17th Annual Meeting of the Scandinavian Society for the Study of Diabetes in Helsingör, Denmark 1982 and at the 18th Annual Meeting of the European Association for the Study of Diabetes in Budapest, Hungary 1982. The investigation was supported by grants from The Swedish Diabetes Association, Stiftelsen Clas Groschinskys Minnesfond and The Swedish Medical Research Council (12X-109). We thank Mrs. A. Nordin for excellent technical assistance in insulin and glucose assays and Mrs. K. Claesson and Mrs. A. Snellman for typing the manuscript.

\section{References}

1. Berg BN (1930) A study of the islands of Langerhans in vivo with observations on the circulation. Proc Soc Exp Biol Med 27: 696-699

2. Bonnevie-Nielsen V, Steffes MW, Lernmark Å (1981) A major loss in islet mass and B-cell function precedes hyperglycemia in mice given multiple low doses of streptozotocin. Diabetes 30: 424-429

3. Buckberg GD, Luck JC, Payne DB, Hoffman JIE, Archie JP, Fixler DE (1971) Some sources of error in measuring regional blood flow with radioactive microspheres. J Appl Physiol 31: 598-604

4. Bunnag SC, Bunnag S, Warner NE (1963) Microcirculation in the islets of Langerhans of the mouse. Anat Rec 146:117-123

5. Bunnag SC, Warner NE, Bunnag S (1977) Vasomotor reactions in the islets affecting the blood glucose levels. Bibl Anat 16:445-449

6. Fischer U, Hommel H, Salzsieder E (1976) Pancreatic blood flow in conscious dogs after oral administration of glucose. Diabetologia 12: 133-136

7. Fischer U, Hommel H, Schmid E (1975) Dynamics of canine pancreatic blood flow and of insulin secretion during an intravenous glucose load. Pflügers Arch 358: 89-100

8. Foun-Chung F, Schuessler GB, Chen RYZ, Chien S (1979) Determinations of blood flow and shunting of 9 - and $15-\mu \mathrm{m}$ spheres in regional beds. Am J Physiol 237: H25 -H33 (Heart Circ Physiol 6): $\mathrm{H} 25-\mathrm{H} 33$

9. Freie HMP, Pasma A, Bouman PR (1975) Quantitative analysis of pancreatic islet development and insulin storage in the foetal and newborn rat. Acta Endocrinol 80: 657-666

10. Greenway CA, Murthy VS (1972) Effects of vasopressin and isoprenaline infusions on the distribution of blood flow in the intestine; criteria for the validity of microsphere studies. Br J Pharmacol 46: $177-188$

11. Gylfe E, Hellman B (1975) The heat production of pancreatic Bcells stimulated by glucose. Acta Physiol Scand 93: 179-183

12. Heding $L$ (1972) Determination of total serum insulin (IRI) in insulin-treated patients. Diabetologia 8:260-266 
13. Hellerström C (1966) Oxygen consumption of isolated pancreatic islets of mice studied with the Cartesian diver micro-gasometer. Biochem J 98: 7C-9C

14. Hellerström C (1967) Effects of carbohydrates on the oxygen consumption of isolated pancreatic islets of mice. Endocrinology 81: 105-112

15. Hellman B (1959) The total volume of the pancreatic islet tissue at different ages of the rat. Acta Pathol Microbiol Scand 47:35-50

16. Hellman B, Sehlin J, Täljedahl I-B (1973) Transport of 3-0-methylD-glucose into mammalian pancreatic B-cells. Pflügers Arch 340: $51-58$

17. Ishise S, Pegram BL, Yamamoto J, Kitamura Y, Frohlich ED (1980) Reference sample microsphere method: Cardiac output and blood flows in conscious rats. Am J Physiol 239 (Heart Circ Physiol 8): H443-H449

18. Jansson L, Hellerström C (1981) A rapid method of visualizing the pancreatic islets for studies of islet capillary blood flow using nonradioactive microspheres. Acta Physiol Scand 113: 371-374

19. Jarrousse C, Jeanrenaud B (1982) Functional differences of the endocrine pancreas due to specific blood supply. Diabetologia 23 : 177 (Abstract)

20. Jirtle RL, Hinshaw WM (1981) Estimation of malignant tissue blood flow with radioactively labelled microspheres. Eur J Cancer Oncol 17: 1353-1355

21. Järhult J, Thulin A (1977) Hyperosmolality and pancreatic blood flow. Pflügers Arch 370: 127-130

22. Kramlinger KG, Mayrand RR, Lifson N (1979) Simple method for visualization of the islets in fixed but otherwise intact pancreas. Stain Technol 54: 159-162

23. Lifson $\mathrm{N}$ (1981) Use of microspheres to measure intraorgan distribution of blood flow in the splanchnic circulation. In: Granger DN, Bulkley GB (eds) Measurement of blood flow. Applications to the splanchnic circulation. Williams \& Wilkins, Baltimore, London, pp 177-194

24. Lifson N, Kramlinger KG, Mayrand RR, Lender EJ (1980) Blood flow to the rabbit pancreas with special reference to the islets of Langerhans. Gastroenterology 79: 466-473

25. Maggi CA, Meli A (1982) Unsuitability of urethane anesthetized rats for testing potential B-adrenoreceptor blockers. Experientia 38: $517-519$

26. Malik AB, Kaplan JE, Saba TM (1976) Reference sample method for cardiac output and regional blood flow determinations in the rat. J Appl Physiol 40: 472-475
27. Maxwell LC, Shepherd AP, Riedel GL (1982) Vasodilation or altered perfusion pressure moves $15-\mu \mathrm{m}$ spheres trapped in the gut wall. Am J Physiol 243 (Heart Circ Physiol 12): H123-H127

28. McCuskey RS, Chapman TM (1969) Microscopy of the living pancreas in situ. Am J Anat 126: 395-408

29. Meyer HH, Vetterlein F, Schmidt G, Hasselblatt A (1982) Measurement of blood flow in pancreatic islets of the rat: Effect of isoproterenol and norepinephrine. Am J Physiol 242 (Endocrinol Metab 5): E298-E304

30. Nishiyama K, Nishiyama A, Frohlich ED (1976) Regional blood flow in normotensive and spontaneously hypertensive rats. Am J Physiol 230: 691-698

31. Phibbs RH, Dong L (1970) Nonuniform distribution of microspheres in blood flowing through a medium-size artery. Can $\mathbf{J}$ Physiol Pharmacol 48: 415-421

32. Rudolph AM, Heymann MA (1967) The circulation of the fetus in utero. Methods for studying distribution of blood flow, cardiac output and organ blood flow. Circ Res 21: 163-184

33. Semb LS, Aune S (1971) The effect of glucose and insulin on pancreatic blood flow in the anesthetized pig. Scand $\mathbf{J}$ Clin Lab Invest 27: 105-111

34. Tsuchiya M, Ferrone RA, Walsh GM, Frohlich ED (1978) Regional blood flows measured in conscious rats by combined Fick and microsphere methods. Am J Physiol 235: H357-H360 (Heart Circ Physiol 4) H357-H360

35. Vance JE (1970) Insulin release and changes in the capillary circulation of the pancreas. Diabetes 19 (suppl): 402 (Abstract)

36. Vetterlein F, Meyer HH, Reitemeyer T, Schmidt G, Hasselblatt A (1981) Blood flow to the pancreatic islets and the influence of isoprenaline, norepinephrine and D-glucose. Diabetologia 21: 339 (Abstract)

Received: 1 November 1982

and in revised form: 21 March 1983

Dr. Leif Jansson

Department of Medical Cell Biology

P.O. Box 571, BMC

S-75123 Uppsala

Sweden 